\title{
REVIEW \\ George Riddoch: the man who found Ludwig Guttmann
}

\author{
JR Silver and M-F Weiner
}

Study design: This is a review article.

Objectives: To evaluate the role played by George Riddoch in the setting up of spinal units in the UK and the appointment of Ludwig Guttmann.

Setting: Wendover, UK.

Methods: Review of the literature and the public records.

Results: Not applicable.

Conclusions: George Riddoch's contribution to our understanding of the treatment for spinal injuries by means of his research on the patho-physiology, treatment and the setting up of spinal injury units in World Wars I and II was outstanding, especially his role in finding, appointing and supervising Ludwig Guttmann at the National Spinal Injuries Centre.

Spinal Cord (2012) 50, 88-93; doi:10.1038/sc.2011.117; published online 1 November 2011

Keywords: George Riddoch; Stoke Mandeville Hospital; spinal injuries; Ludwig Guttmann

\section{INTRODUCTION}

Sir Ludwig Guttmann (1899-1980), the founder of the treatment for spinal injuries, was very sparing with his praise, yet he dedicated his book on the comprehensive management of spinal injuries to George Riddoch, with the following words:

'This book is dedicated to the memory of Dr George Riddoch (1888-1947), Neurologist, The London Hospital and the National Hospital for Nervous Diseases. Pioneer Advocate of Specialized Units for the Treatment of Sufferers from Spinal Cord Lesions. ${ }^{1}$

Having treated soldiers with spinal cord injuries during the First World War, Riddoch made an outstanding contribution to our understanding of the reflex changes, following a transection of the spinal cord and the practical management of patients.

There is little information on Riddoch's involvement in the treatment of spinal injuries, and the setting up of spinal units during the Second World War in his obituaries and historical accounts of Queen Square, and the authors had to study public records from the Ministry of Health and the Emergency Medical Services to obtain evidence on how Riddoch was personally responsible for Guttmann's appointment to Stoke Mandeville Hospital, where the first comprehensive care for injuries to the spinal cord was developed. Riddoch died prematurely at the age of 58, without receiving the accolades of FRS or a knighthood. Reference to him in the literature is scarce, but his outstanding contribution to spinal injuries warrants further investigation.

\section{GEORGE RIDDOCH MD, FRCP (1888-1947)}

Riddoch accomplished much in a short life (Figures 1 and 2). Born in Banffshire, he was educated in Scotland, and qualified in medicine with first class honours from Aberdeen University in 1913. While there, he was appointed as a demonstrator in the anatomy department and acquired a thorough knowledge of anatomy, which served him in good stead for his subsequent career as a neurologist. He obtained his MD in $1917 .^{2}$ He went to London as a resident at the West End
Hospital for Nervous Diseases (without doing a junior general or medical or surgical job), a pioneering hospital for the treatment, and research in psychiatric and neurological disorders, where he gained invaluable experience working with Harry Campbell (1860-1938) and James Purves-Stewart (1869-1949). A doctor with neurological training, such as Riddoch, was very rare in those days (Gordon Holmes was the sole neurologist in the British Army). As a result, in 1914, during the First World War, Riddoch was appointed as a captain in the army, with duties of an officer in charge of injuries of the nervous system at the Empire Hospital for Officers. Riddoch together with the visiting consultants, James Collier (1870-1935), Frederick Eustace Batten (1866-1918), Sir Edward Farquhar Buzzard (1871-1945), Leonard George Guthrie (1858-1918), Henry Head (1861-1940) and Kinnier Wilson (1878-1937) treated patients with spinal injuries, traumatic neurasthenia and shell shock. Head soon recognised Riddoch's neurological ability, and a long and fruitful partnership ensued, resulting in a collaborative paper on 'The autonomic bladder, excessive sweating and reflex conditions in gross injuries of the spinal cord' (1917). ${ }^{3}$

After the 1914-1918 war, having established a firm reputation as a neurologist, Riddoch sought to further his clinical experience, and through the Medical Research Council (MRC) he joined the newly formed Medical Unit at the London Hospital and also worked at the Hospital for Epilepsy and Paralysis in Maida Vale. In 1924, he was elected as a supernumerary assistant physician to the London Hospital, and was appointed to the staff of the National Hospital, Queen Square. ${ }^{4}$ In the inter-war years, he built up a very successful private practice and with Lord Dawson of Tenn, they boasted the largest incomes in London. ${ }^{5}$

When the Second World War broke out, the neurological unit of the London Hospital was evacuated to the Chase Farm Hospital in Enfield, where Riddoch was appointed as the head of the Emergency Medical Services (EMS), neurological unit. In 1941, Riddoch accepted a commission as a Brigadier and with Cairns, he devoted himself to 


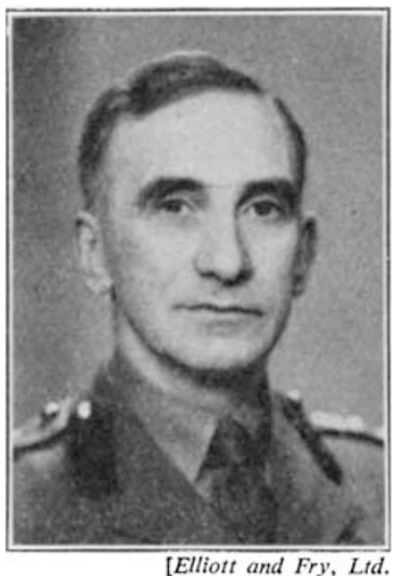

Figure 1 Brigadier George Riddoch during the Second World War. Reproduced by kind permission from the Wellcome Library, London.

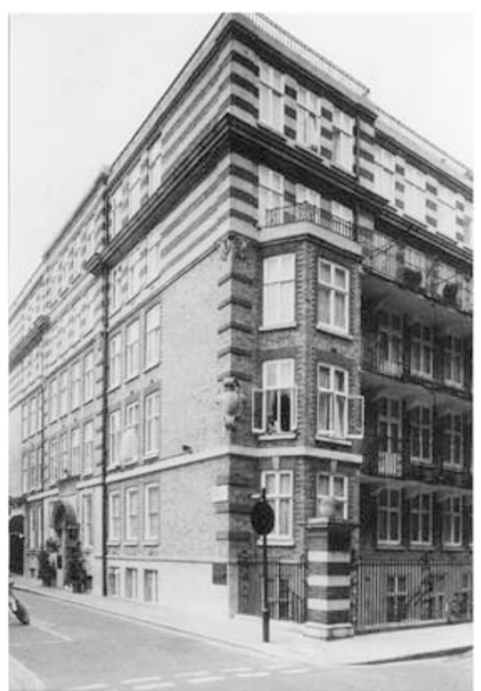

Figure 2 The Empire Hospital, which was not built as a hospital and is now a private hotel. (C) Crown copyright. NMR.

the organisation of the Army neurological service. He was a member of the War Office Medical Board and chaired the Nerve Injuries Committee for the Medical Research Council. In 1941, Riddoch was appointed as a chairman of the MRC Peripheral Nerve Injury Committee. $^{6}$ In 1943, he drafted an MRC booklet on the investigation of peripheral nerve injuries (this is still in use today in its 6th edition). Subsequently, a separate subcommittee was set up, comprising of Brigadier Riddoch, Professor Platt, Group Captain Symonds and Colonel Cairns, to deal exclusively with spinal injuries. This led to the publication of a memoranda issued by the Ministry of Health Emergency Medical Services, in 1944, on 'Injuries to the Spinal Cord and Cauda Equina and their Treatment."

Riddoch's scientific contribution to the physiology of the transected spinal cord

Before the First World War (Table 1), traumatic injuries of the spinal cord were rare and few patients survived long enough for the condition to be studied. In 1890, Bastian had argued that the isolated spinal cord was incapable of reflex activity. He postulated that 'muscular flaccidity and absence of tendon reflexes in the lower limbs is the permanent result of total transverse lesions of the spinal cord in the lower cervical and upper dorsal regions.' ${ }^{8}$ This loss of total reflex activity became widely accepted until 1906, when Sherrington published his seminal book on The Integrative Action of the Nervous System, which described reflex action in animals and further delineated the function of the spinal cord. ${ }^{9}$ It was only with the advent of the First World War, which saw many patients with spinal cord transections, that the significance of Sherrington's work could be fully appreciated and that it could be applied to humans. This was largely as a result of, Head, Riddoch and Holmes's work.

In 1914, Head was acknowledged as the foremost research worker and teacher on the central nervous system in the United Kingdom. Head collaborated with Riddoch and encouraged him to study the function of the spinal cord. The war afforded an unparallel opportunity to observe such cases, and Riddoch was able to study a group of eight patients with completely divided spinal cords (verified at operation) and show, contrary to Bastian's views, that reflex action as described by Sherrington was present in humans as well. ${ }^{10}$ His meticulous studies on reflexes showed that the completely divided spinal cord passed through several stages, initially with an absence of tendon reflexes (spinal shock) but these returned at a later stage. ${ }^{11,12}$ The reflexes were shown to be subject to the same rules as in animals. Riddoch studied what he considered to be analogous reflexes in the upper limbs, and described a Babinski response in the upper limb, with rotation of the shoulder and extension of the fingers. He described the mass reflex in paraplegia involving the musculature of the abdominal wall. (Mass reflex: this takes the form of a vast outburst of motor energy not confined to the parts stimulated, overflowing into visceral channels, a profound shrinking away of the animal from harmful stimulation. Not only is the spread of this reflex activity greater than that under normal conditions, but the receptive field from which it can be evoked is also unlimited below the lesion in favourable cases. ${ }^{13}$

Head and Riddoch made detailed observations on the bladder function. They described all the phenomena of autonomic dysreflexia, noting the dilatation of the pupils, the irregular slow pulse, the ringing in the ears, the bradycardia, the headaches, the evacuation of the bladder, the excessive sweating, and how these symptoms could be evoked by distension of the bladder or painful catheterisation. They failed to correlate autonomic dysreflexia with a rise in blood pressure mainly because blood pressure was not recorded routinely in those days (Krotokov signs for the measurement of the blood pressure were only described in 1905). Consequently, the correlation of distension of the bladder with autonomic dysreflexia was not linked to the cardiovascular system.

Holmes, in 1915, regretted that the blood pressure was not measured routinely and in a few cases he noted that it was low in cases of spinal shock, following gunshot wounds, but unfortunately he only measured the blood pressure on three occasions and that on those occasions, only the systolic pressure was recorded. (In 1944, Guttmann was carrying out experiments in Oxford on distending the bladder. He measured the blood pressure, saw that it was raised and rushed into the adjacent laboratory, where Whitteridge was working. 'Look!' he said, 'we must make a study of this'. They worked together and measured simultaneously blood flow, blood pressure, bladder pressure and thus delineated autonomic dysreflexia. They assembled a large research team, including Phillips CG, McAdam W, Taylor KP, Torrance RW and Wall PD, who told me that his role as a medical student was to use a stopwatch for some of the observations (personal communication with Wall 30 years ago). This link to a rise in blood 
Head H, Riddoch G. The automatic bladder, excessive sweating and some other reflex conditions in gross injuries of the spinal cord G. Brain 1917 ; 40 : 188.

Riddoch G. Reflex functions of the completely divided spinal cord in man (compared with those associated with less severe lesions). Brain $1917 ; 60: 264-402$.

Riddoch G. Hypotonia and Trophic Changes. Presentation to the RSM at a meeting of the Section of Neurology, British Medical Journal report on Societies. BMJ Review Reports and Societies, 20 April 1918, p 455.

Riddoch G. Functional nervous diseases. In: Crichton Miller H (ed). Chapter in Functional Nerve Disease: An Epitome of War Experience for the Practitioners. Hodder \& Stoughton: London, 1920.

Riddoch G, Buzzard EF. Reflex movements and postural reactions in quadriplegia and hemiplegia, with especial reference to those of the upper limb, Brain 1921; 44: $397-489$. Riddoch G. The clinical picture of complete transverse division of the spinal cord. Medical Science 1921; 5: 44-52.

Campbell Thompson H, Riddoch G. Diseases of the Nervous System. Cassell \& Co: London, 1925, pp 170-174.

Riddoch G. Orthopedic section. Proceedings of the RSM Meeting on Spinal Injuries, vol. 46; 6 December 1927. 1928 , pp 637-644.

Lumleian RG. Lectures on pain of central origin, delivered before the Royal College of Physicians on 14 and 17 March 1938 . Reprinted from The Lancet, 14 May 1938, p 1093; 21 May 1938, p 1150; 28 May 1938, p 1205.

Riddoch G. Phantom limbs and body shapes. Brain 64; December 1941, pp.197-222. 1941.

Riddoch G, Rowley Bristow W, Cairns HWB et al. Aids to Investigation of Peripheral Nerve Injuries. Medical Research Council: London, $1943, \mathrm{p} 54$.

pressure had important implications, as washing out the bladder could cause fatal autonomic dysreflexia. $)^{14}$

At the end of the war, Riddoch returned to clinical practice, but maintained his interest in spinal conditions and presented papers at the Royal Society of Medicine (RSM). He gave the prestigious Lumelian address to the Royal College of Physicians (Lancet 1938), in which he discussed the importance of the posterior columns and the posterior nerve roots in the production of pain, with a detailed description of Foerster's experimental work. He also described pain and phantom limbs in paraplegic patients in great detail. ${ }^{15}$

\section{Riddoch's contribution to the treatment of spinal injuries}

First world war. When Riddoch was appointed officer in charge of the Empire Hospital, he worked single-handedly and was responsible for every aspect of patient care. He thus gained a unique insight into the practical management of spinal injury patients. His experience in managing the patients is reflected in his scientific papers, which were much more fulsome in those days and not just restricted to a dry description of his findings but described in detail the management of the patients. He addressed the management of the bladder, the prevention of pressure sores and spasms, and the need for exercise.

\section{Bladder management:}

Riddoch recommended intermittent catheterisation with strict aseptic precautions, and he described in detail how the bladder should be washed out four times a day. He recognised the dangers of over-distension of the bladder: potentiating the motor paralysis of the bladder, the dangers of retention leading to cystitis and pyelonephritis, and the danger of infection within the bladder, which, owing to its defective emptying, could give rise to fulminating ascending infection of the kidneys and septicaemia, and death. He described how: 'A bladder, which had never been distended or subjected to the ravage of septic infection, reacted reflexly as a rule to a larger amount of fluid than did a bladder whose musculature had been stretched by initial distension or by careless manipulation or had deteriorated owing to repeated attacks of cystitis. ${ }^{10}$

In an early description of autonomic dysreflexia, Riddoch described how sweating could be initiated by distension of the bladder, enemas, the coitus reflex or a change in position. ${ }^{10}$

However, he did not mention suprapubic catheterisation or cystotomy.
2. Prevention of pressure sores:

Riddoch was aware of the dangers of pressure sores in the acute stage when the blood supply of the skin was compromised, and overwhelming sepsis could kill the patient. ${ }^{10} \mathrm{He}$ understood that pressure sores could also lead to sepsis leading to septicaemia and death. He advocated regular changes in position, and recognised the virtues of sitting up with the aid of a pulley and exercise in the open air but did not mention the need for debridement or surgery (note: debridement was later recommended in case of gunshot wound in the 1944 memorandum). He described thrombosis of the legs, and how undue movement could cause pressure sores and he recommended regular changing of the dressings.

3. Prevention of spasms:

He was aware of the danger of spasms, and the need to prevent them as the repetitive movements of the patient's knees one on the other and the heels on the bed could give rise to pressure sores. ${ }^{10}$

Between the wars. At the end of the war, Riddoch left the army and although he ceased treating spinal injury patients at the Empire Hospital, his knowledge of spinal injury management was in demand. At a symposium on spinal injuries at the Royal Society of Medicine (1927), he stressed how important it was in spinal fractures to establish whether the spinal cord was involved or not. Riddoch gave detailed descriptions of the indications for laminectomy, a subject that he had not discussed in his First World War papers. ${ }^{16}$ He recommended a laminectomy in cases of extra meningeal haemorrhage, or driven segments of bone but not in cases of bullet displacement or in the presence of overwhelming sepsis.

Riddoch wrote a chapter in a textbook with Campbell Thompson, where he refers only briefly to the treatment of traumatic paraplegia, but equates it to the treatment of transverse myelitis, where he recommends washing out the bladder and turning the patient regularly, and when treating pressure sores, changing the dressings frequently. ${ }^{17}$

Second world war. National plans for spinal injury units: By 1936, war with Germany was inevitable and preparations were made to treat the expected casualties. At the outbreak of the Second World War, despite the knowledge gained from the previous conflict, there were no specialised spinal units to treat the patients. Spinal injuries were recognised as special cases. Riddoch's practical experience of spinal 


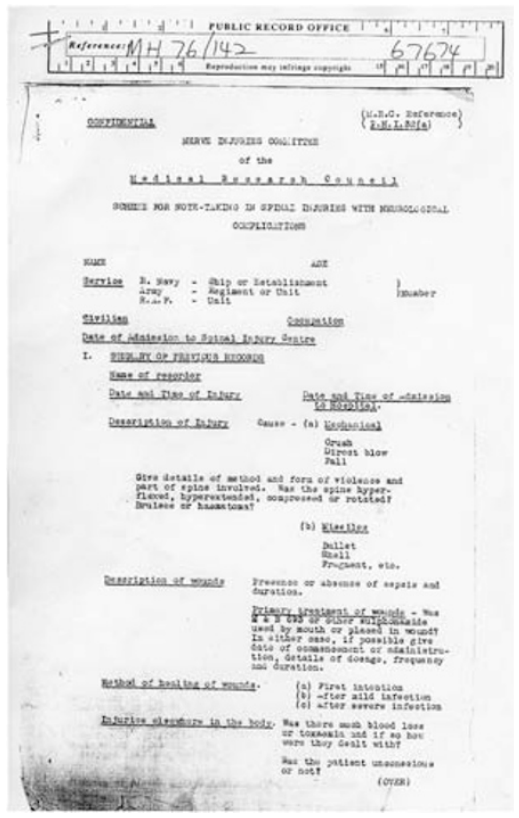

Figure 3 Memoranda issued by the Nerve Injuries Committee of the Medical Research Council and sent to all hospitals admitting spinal injury cases. This was a form designed to collect information on every case admitted with a spinal injury. The importance and difficulties of accurate record keeping was recognised from the outset; nothing has changed (London Public Record Office MH76/142).

injuries during the First World War and his continued research between the wars made him the ideal doctor for the nationwide management of spinal injury patients during the Second World War. (Gordon Holmes, who had a comparable experience, was already too old to undertake such a demanding role.) ${ }^{6}$

A distinction was made between an acute spinal trauma patient (where a patient was suffering from major intercurrent trauma) and long-term incurable patients. The former would require resuscitation, bone and spinal cord surgery, access to pathology and radiography departments, and all the facilities of a properly appointed neurosurgical and orthopaedic unit. No mention was made of the urologist.

In 1940, four acute units were designated to receive casualties.

- Agnes Hunt and Robert Jones Hospital, Oswestry, serving the Midlands

- Royal National Orthopaedic Hospital, Stanmore, serving London

- EMS Hospital Winwick, Warrington, serving the North West

- Bangour Hospital, serving the whole of Scotland

A further 12 units were set up for chronic cases:

'Gradually, 12 spinal units were set up in various parts of the country, where most of the 700 odd casualties with spinal cord injuries were collected (Winwick, Warrington; Barnsley Hall; Park Prewett, Basingstoke; Wharncliffe, Sheffield; Chapel Allerton, Leeds; Ronkswood, Worcester; Dunstan Hill, Newcastle; Rookwood, Cardiff; Llandrindod Wells, Stanmore, London; Leatherhead, Surrey; and Bangour, Edinburgh).' 6

The Memoranda: Riddoch instigated the distribution of two memoranda (Figures 3 and 4), one describing how cases should be recorded when first presented, and another giving directives for the treatment of spinal injury patients.

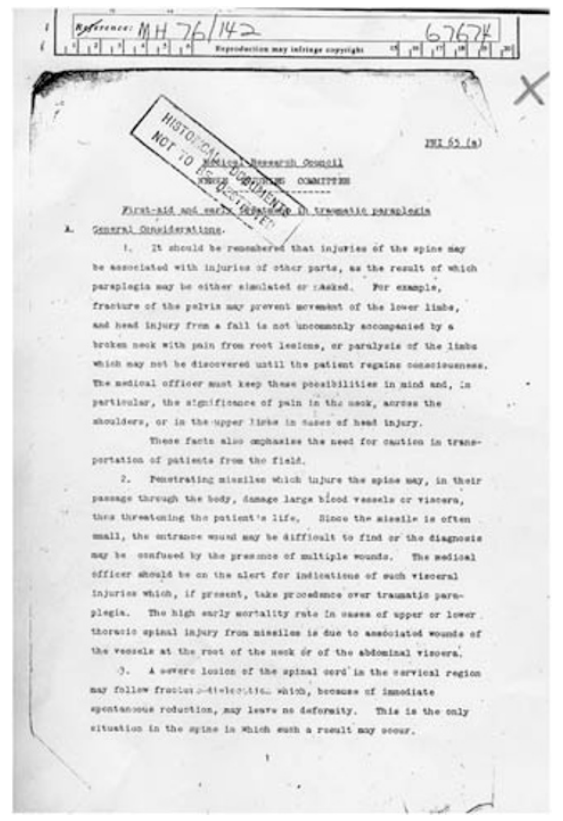

Figure 4 Memoranda issued by the Nerve Injuries Committee of the Medical Research Council, giving guidance on how to treat patients suffering from traumatic paraplegia. (London Public Record Office MH76/142).

Scheme for Note-Taking in Spinal injuries with Neurological Complications

Riddoch understood the importance of research and was keen to gather as much information as possible on spinal injuries, he devised a form in 1942 (DGL77F) modelled on a similar document used for the follow-up of peripheral nerve injuries (letter to Fraser from Riddoch dated 12 August 1943, MH76/142). ${ }^{18}$ This was sent to every unit caring for spinal injury patients to record each case history, examination, treatment regime, possible complications and progress report. Whether this data was ever recorded and analysed is not known.

Although specialist units had already been established, these were not properly staffed and run, and as there were no textbooks on the subject they issued a memorandum with advice on treatment.

The Ministry of Health Emergency Medical Services Memorandum on Injuries of the Spinal Cord and Cauda Equina and their Treatment, in 1944

Riddoch and Holmes's input into the 1944 memorandum was paramount and their advice is palpable throughout although they were not always in agreement with all the recommendations. ${ }^{19}$

The main problem was the management of the bladder. Doctors did not understand the physiology of the bladder and did not distinguish between the atonic bladder in cases of cauda equina and the automatic bladder in cases where the reflexes are intact. The memorandum recommended intermittent catheterisation, wash-outs and tidal drainage, but if too near the battle front they recommended an indwelling catheter. They were opposed to manual expression. They recognised the dangers of infection of the bladder spreading to the kidneys and the risks of over distension of the bladder, they believed that infection was less severe when reflex function had returned to the bladder and it could empty itself. They were not in favour of a supra-pubic cystotomy unless urethritis or prostatitis had already occurred. 
Gordon Holmes, who was also involved in managing spinal injuries in the First World War, was in favour of supra-pubic cystotomy. Riddoch had warned against the distension of the bladder and described its consequences.

With regard to pressure sores, H.A.T. Fairbank, Holmes and Riddoch were opposed to the use of plaster beds, but were voted down by orthopaedic surgeons.

\section{Riddoch's visits to spinal units in the United Kingdom}

Between 1942 and 1945, Riddoch endeavoured to set up specialised units for the treatment of war casualties with spinal cord injuries and peripheral nerve injuries, and his correspondence forms a large part of the 539 letters and memoranda consulted at the Public Record Offices. He was in frequent communication with numerous EMS orthopaedic surgeons and doctors at the Ministry of Health, especially professor Fraser. Not only did Riddoch co-ordinate and oversee the provision of care in the whole country but was also personally involved in visiting hospitals and assessing their suitability with regard to their location, staffing, facilities and size. He visited Hayward's Heath (1942), Horton Mental Hospital (1943) and Stanmore (1944), and in August 1944 alone, he went to three units over a 4-day period, Newcastle, Winwick and Gateshead, and presented detailed proposals for each. He took an active part in numerous meetings and mentored the doctors concerned. He was a busy overworked sick man, constantly on the move.

His practical suggestions included the provision of 'flat areas of garden', accessibility for wheelchairs, segregation of men and women, the provision of specialised staff, orthopaedic surgeons, neurosurgeons, urologists, neurologists, trained nurses and physiotherapists, but also the need to train the patients for future rehabilitation. The requirements were so specific and the work involved was so painstaking that the short list of suitable units underwent numerous revisions over those 3 years. He was courteous, objective and persuasive, rallying others to his cause. Realistic and practical, he offered to send Seddon, a neurologist for training on a 'secondment' basis or 'exchange' so as not to disrupt the hospital routine.

Riddoch was the only person who knew how to look after the spinal injury patients, and he was trying to run all the spinal units by proxy but could not oversee them personally. He could issue directives in memoranda against plaster beds and advocating supra-pubic cystotomy, but he was not an officer in charge as he had been at the Empire Hospital during the First World War, and could not ensure that his instructions were carried out. Despite his efforts, the treatment in all

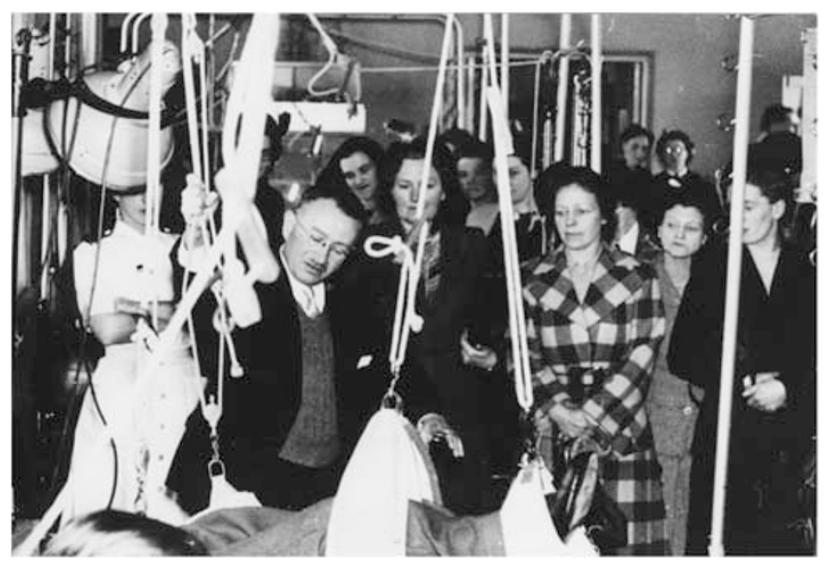

Figure 5 Ludwig Guttmann at his happiest, teaching physiotherapists at Stoke Mandeville Hospital (personal photograph). the units was appalling. This was substantiated by Dick, who worked at Winwick and described patients covered in pressure sores, who after 3 years of treatment were no better than when they first arrived, and Riches, who was commissioned to visit all these units. ${ }^{20,21}$

Riddoch and the setting up of Stoke Mandeville Hospital, and Guttmann's appointment and Guttmann's research

Units were set up in the North of the country in 1940 but provision for the South of England was delayed (Figure 5). Plans to set up a unit at Wingfield Morris to serve the South of England failed because Seddon refused to release beds. Stoke Mandeville and Park Prewett were considered although Stoke Mandeville did not have a neurologist to support the staff, and Riddoch offered his services as a neurologist. ${ }^{22}$ Despite all these efforts, by 1943 there was still no unit although there is a cryptic account of patients being admitted to Stoke Mandeville with spinal injuries under Dr MacDonald, a resident Medical Officer of only 6 months.

It was only when Riddoch appointed Guttmann to take charge at Stoke Mandeville that an effective unit emerged. ${ }^{23}$

Born in Silesia, Guttmann was trained under Foerster in neurology and rehabilitation. When the Nazis came to power in 1933 Guttmann, a Jew, was expelled from his job under racial laws. He gained administrative experience running the Jewish Hospital in Breslau from 1933 to 1939, but fled Nazi Germany in 1939 and took refuge in Oxford, where he worked under Cairns in the Nuffield Department of Neurosurgery. After 5 years of research, Guttmann was eager to treat patients and had the perfect opportunity to put into practice what he had learned under Foerster in Germany on the rehabilitation of peripheral nerve injuries. He successfully adapted these principles to the treatment of spinal injuries in the United Kingdom. ${ }^{6}$

Guttmann had written a survey on the treatment of spinal patients for Riddoch and subsequently, Riddoch had heard him speak on the rehabilitation of peripheral nerve injuries at the RSM in 1941 (Scrutton, ${ }^{24}$ p 11 and Guttmann ${ }^{25}$ ). Riddoch recognised Guttmann's potential, and in February 1944 he invited him to run the newly formed spinal unit at Stoke Mandeville Hospital, telling him 'you will have to start from scratch' (Scrutton, $\left.{ }^{24} \mathrm{p} 11\right)$.

Scrutton described how:

'In all this gloom there loomed one ray of hope, these patients were to have a full time medical officer' (Scrutton, ${ }^{24}$ pp 12-13).

Guttmann's main philosophy was to take personal charge of each and every patient on arrival, and monitor their progress daily to ensure treatment was done according to his precepts. Not only was he an inspirational doctor, leader and teacher but he also found time to carry out research.

Guttmann instituted a revolutionary physiotherapy regime and incorporated sport in the rehabilitation of the patients. Despite the poor facilities at his disposal, Guttmann's very successful and innovative ideas brought him wide recognition and his methods of treatment were emulated worldwide. By 1949, Winner acknowledged that Stoke Mandeville was the only satisfactory unit in the United Kingdom with an 'embarrassing number of applications for admission as a result of its high reputation.' ${ }^{26}$

Riddoch personally sponsored Guttmann and organised a grant from the MRC to support his work on autonomic dysreflexia. ${ }^{27}$ He helped him to obtain equipment for his research and regularly visited the unit. Riddoch, as the foremost neurologist in the country, personally saw that Guttmann, a foreigner, a Jew and an outsider, should be accepted by the establishment. ${ }^{28}$ After Guttmann was appointed, Riddoch supported his work and encouraged him to submit his research on autonomic dysreflexia. Guttmann acknowledged this support by dedicating his book to Riddoch. ${ }^{1}$ 


\section{EVALUATION OF RIDDOCH'S LEGACY}

Riddoch's involvement in spinal injuries does not follow a linear progression, from his role in the hands-on treatment of spinal injury patients during the First World War to contributions to seminars on spinal injury management between the wars, his writings and his lectures, and finally the culmination the during the Second World War with the setting up of the Stoke Mandeville spinal unit and the appointment of Ludwig Guttmann. Riddoch knew how to look after the spinal injury patients because of his experience during the First World War. When the war ended, there was no National Health Service. The war pensioners were cared for on a custodial basis at the only spinal injury unit that remained (the Star and Garter), JW Thomson Walker, the only practising urologist did not visit them regularly. Riddoch, like Holmes and $\mathrm{Head}$, returned to private practice. After the war, specialised units for plastic surgery, burns, jaw surgery and neuropsychiatry all closed down. ${ }^{6}$

It was an extraordinary achievement that within 3 years of qualifying, Riddoch produced seminal papers in Brain, a prestigious journal, with the most beautiful descriptions of cases, interposed with clinical observations on how to treat the patients and wonderful descriptions of the return of the reflex function. This was because he had personal experience of treating patients at the Empire Hospital. These accounts described early cases of autonomic dysreflexia often quoted in the literature.

Riddoch's clinical descriptions of the reflex changes are excellent. $\mathrm{He}$ described reflexes in the upper limb, analogous to the Babinski response, and in the lower limbs, the flexion reflex supposed to be found in incomplete lesion and extension reflex in complete lesion. Despite criticism by Russell Brain, Riddoch's description of the mass reflex and autonomic dysreflexia without the blood pressure changes have stood the test of time as has his description of phantom limbs.

When the Second World War broke out, Riddoch wanted to provide treatment facilities for spinal injuries but he did not have the administration or rehabilitation training that Guttmann had. The knowledge was there and Riddoch described it very clearly but it was the implementation, which was the problem because Riddoch was reared in the English tradition, he did not have Guttmann's resolve, bullying and leadership qualities to achieve the same result. Guttmann had the vision, the resolve, and the ability to achieve it. All the other units failed because no one knew how to look after the patients, and it is only when Riddoch found Guttmann, who was trained by Foerster, that proper treatment could be administered.

Forester was not only a great neurologist and a neurosurgeon, but he was also unique in that he was trained by Frenkel in rehabilitation and he in turn trained Guttmann. When Guttmann came to England, no one in this country was trained in rehabilitation and when Riddoch appointed Guttmann, he was appointing not only a neurologist but also someone who knew about rehabilitation and how to look after spinal injury patients. All the other units that had been set up before failed because they did not have any trained staff at any level, and the officers put in charge of these units were just administrators, they did not have the knowledge to look after the patients unlike Guttmann who knew how to do it and trained the staff.

At the end of the war, Guttmann stood at the celebratory fireworks and said to the pathologist Greenbury: 'It's such a pity that we are only just starting the work with spinal patients', but as the Ministry of Pensions kept the spinal unit going and the NHS was set up, the work could continue (L Greenbury, personal communication, 1972).
Riddoch's greatest contribution according to Pennybacker was finding Guttmann and setting up Stoke Mandeville so that everyone could learn by example.

\section{CONFLICT OF INTEREST}

The authors declare no conflict of interest.

\section{ACKNOWLEDGEMENTS}

I am grateful to Mr Jonathan Evans (archivist at the London Hospital), Mr King (archivist for the Society of British Neurological Surgeons), Mr Philip Harris, Dr George Storey and Lord Walton, for their invaluable help with my research, and to the Wellcome library for granting permission to reproduce an illustration of George Riddoch, and English Heritage for granting permission to reproduce an illustration of the Empire Hospital.

1 Guttmann L. Spinal Cord Injuries Comprehensive Management and Research, 1st edn. Blackwell Scientific Publications: Oxford, London, Edinburgh and Melbourne, 1973.

2 Riddoch G Certain visual disturbances due to occipital injuries, with special reference to appreciation of movement and to dissociations between visual perceptions. Unpublished MD thesis, Library and Historic Collection of Aberdeen University, 1917

3 Head H, Riddoch G. The automatic bladder, excessive sweating and some other reflex conditions in gross injuries of the spinal cord. Brain 1917; 40: 188

4 Storey GO. George Riddoch (1888-1947). J Med Biogr 2010; 18: 35-37.

5 Pennybacker J Section on Queen Square in a 2 volume memoir, unpublished manuscript c. 1976.

6 Silver JR. The History of the Treatment of Spinal Injuries. Kluwer Academic/Plenum Publishers: New York, 2003, pp 25, 70, 71.

7 Emergency Medical Services Memorandum. Injuries of the Spinal Cord and Cauda Equina and their Treatment. London Public Record Office, 1944 MH76/142.

8 Bastian HC. On the symptomatology of total transverse lesions of the spinal cord, with special reference to the condition of the various reflexes. Trans Med-Chir Soc 1890; 72: 151.

9 Sherrington C. The Integrative Action of the Nervous System, 1st edn. Charles Scribner's Sons: New York, 1906.

10 Riddoch G. Reflex functions of the completely divided spinal cord in man, compared with those associated with less severe lesions. Brain 1917; 60: 264-402.

11 Riddoch G, Buzzard EF. Reflex movements and postural reactions in quadriplegia and hemiplegia, with special reference to those of the upper limb. Brain 1921; 44: 397-489.

12 Riddoch $\mathrm{G}$. The clinical picture of complete transverse division of the spinal cord. Med Sci 1921; 5: 44-52.

13 Head H. Gross injuries of the spinal cord. In: Studies in Neurology. Oxford University Press: London, 1920, p 503.

14 Holmes G. On spinal injuries of warfare-Goulstonian Lectures. Br Med J 1915; 2 : 769-774, 815-821, 855-861.

15 Riddoch G. Lumleian Lectures on Pain of Central Origin, delivered before the Royal College of Physicians, London, on 14 and 17 March 1938. Reprinted from The Lancet, 14 May 1938, p. 1093; 21 May 1938, p 1150; 28 May 1938, p 1205.

16 Riddoch G Orthopedic Section. Proceedings of the RSM Following a Meeting on Spinal Injuries; 6 December 1927. Published in 1928; 46: 637-644.

17 Campbell Thompson H, Riddoch G. Diseases of the Nervous System. Cassell \& Co, 1925, pp 170-174.

18 Riddoch G. Letter to Fraser regarding the follow up of patients with spinal injuries. London Public Record Office, 12 August 1943, MH76/142.

19 Memorandum issued by the Medical Research Council - Nerve Injuries Committee on the treatment of traumatic paraplegia. London Public Record Office, 1944, MH76/142.

20 Dick TBS. Rehabilitation in chronic traumatic paraplegia - a clinical study. MD thesis, Victoria University of Manchester 1949.

21 Riches E. Tribute to Sir Ludwig Guttmann. Paraplegia 1969; 7: 158-159.

22 Riddoch G. Letter offering his services as a neurologist for Stoke Mandeville Hospital. London Public Record Office, 22 January 1943, MH76/142.

23 Riddoch G. Correspondence with Fraser. London Public Record Office, 2 July 1943, $\mathrm{MH76/142.}$

24 Scrutton J. Stoke Mandeville - Road to the Paralympics. Peterhouse Press: Brill, Aylesbury, England, 1998.

25 Guttmann L. Discussion on rehabilitation after injuries to the central nervous system. Proc R Soc Med 1941; 35: 305-308.

26 Winner A. Report on Spinal Units for the Ministry of Health. London Public Record Office, 1949, MH58/653 Appendix A and B.

27 Riddoch G. Research Application Forms and Correspondence. London Public Record Office, 1944, FD1/6555.

28 Riddoch G. Correspondence. London Public Record Office, 1945, MH76/142. 